its effect also. The general effect is to form fine halo and shadow fringes near the boundaries of phasechange in the object. Zernike has discussed similar effects in his papers, showing how it is that small opaque particles may sometimes appear bright on a dark ground, drawing their light from neighbouring parts of the field.

But the problem grows much more complex when the object is thicker; the sum of the diffracted light may have no easily predictable phase-relation with the incident light, and could thus be spoken of as 'scattered' in that special sense. The halo and fringe effect may therefore be complex, and although the broader regions of uniform phase should still be rendered at the appropriate brightness levels in the image, we cannot interpret the fringes in the same way in every case. The statement above, that the brightness of the image field is related to the retardation of the object, does not apply to the variations of brightness in the border fringes, and the possibility of estimating the retardation does not apply to relatively small objects.

Enough has been said to indicate that the practical technique must be studied in relation to special objects. The simple theory only takes the worker a part of the way, and there is room for a considerable amount of further work both theoretical and practical. However, all the evidence shows that 'phase-contrast' is a most valuable addition to the methods available to the microscopist, and it is being intensively studied at the present time. One of Zernike's own papers (Physica, 9, 686 and 974; 1942) gives the best starting-point.

\section{MARINE BIOLOGY AT PLYMOUTH*}

7 HE Marine Biological Association of the United Kingdom came into being in 1884 as a result of a meeting held under the chairmanship of Prof. T. H. Huxley, the successive outcome of which owed much to the initiative and energy of Sir E. Ray Lankester. The prime purpose of the Association was "the establishment and maintenance of a well-equipped laboratory at a suitable point on the English coast, similar to, if not quite so extensive as, Dr. Dohrn's Zoological Station at Naples". The suitable point finally selected was Plymouth, and there, under the walls of the Citadel built by Charles II and overlooking the waters of Plymouth Sound, the laboratory building, constructed of the same Devonian coral limestone as the Hoe, was opened on June 30, 1888.

Financial support came initially from members of the Association, from universities and other public bodies, notably the Fishmongers' Company, and from H.M. Treasury. All these sources of income have been maintained and increased, but especially the Treasury grant, which became considerable after 1918, when it was put under the control of the Development Commissioners. In 1902 the Association undertook the British share of the scientific investigations of the International Council for the Exploration of the Sea, which involved the establishment of a second laboratory at Lowestoft for work on the trawling grounds and food fishes of the southern North Sea. After 1918 this laboratory was reestablished under the Ministry of Agriculture and Fisheries for work on problems dealing directly with

* Substance of a lecture by Wing-Commander F. S. Russell, F.R.S., delivered at the Royal Society on March 6 . commercial fisheries. The Plymouth Laboratory was to be concerned with the more fundamental problems of marine research, and to this end notable increases were made to the staff, buildings and facilities of the Laboratory in the years between the two World Wars.

The papers published in the Journal of the Association, now in its twenty-sixth volume with two earlier volumes in a smaller format, indicate the changing interests and widening scope of the work carried on in the Laboratory. Earlier volumes are largely concerned with observations on the habits of fishes and shellfish and on the methods and results of commercial fisheries. Aided by enthusiastic visiting workers, the basis was also being laid of the extensive knowledge of the marine life of the Plymouth area now recorded in the "Plymouth Marine Fauna" (second edition, 1931). With the assumption of the work for the International Council opportunities came for initial studies on hydrography, on bottom fauna and on plankton. A notable change comes in the subject-matter of the Journal after 1918, with emphasis on the study of the chemical and physical conditions of the environment, on the life-histories and development of marine invertebrates and on the distribution in space and time of the animal populations. Nevertheless, research on the biology of fishes continued and provided a necessary link with the more economic investigations being carried out at Lowestoft. But recognition of the value of fundamental research had been achieved. To-day we are approaching the stage when all fisheries research will become increasingly fundamental, aimed at understanding the great natural fluctuations in the fish populations and the causes of the habits of the fish themselves.

The Plymouth Laboratory has provided the basis for such far-reaching studies by the concentration of its work around two main themes. The first is how much living matter can the sea produce, what are the variations and causes of variation in productivity, and how do the organisms obtain the materials necessary for life? The second is how do marine animals live, how do they fit their various environments, and what alterations in the conditions in their environment can they appreciate? The sea water contains all the ingredients needed for successful growth and development of living organisms; it is the conditions in the water which therefore determ. ine their distribution and migrations.

The study of the physics and chemistry of the sea has thus become a major preoccupation. The approximate yearly cycle of the more abundant constituents -phosphorus, nitrogen and silicon-is now known, although much remains to be done on the annual turnover and on periodic fluctuations. This in turn involves a study of water movements, especially of upwelling from deep layers. Plant life depends on light and is limited by the depth of its penetration; this is being studied by methods employing photoelectric cells. Meanwhile, pure cultures of diatoms and flagellates are used as experimental material for determining the utilization of combined nitrogen and phosphorus, and the effect of trace elements such as iron and manganese, which may limit plant pro. duction in the sea.

Animal plankton forms the first link of the chain from plant plankton to fish, and researches on its distribution, abundance, growth and habits form a necessary part of the study of the general problem of productivity. The effects of grazing off the plant 
crops can be studied at sea by evaluation of their numbers in measured volumes of water and also experimentally in the laboratory. Certain species of plankton organisms are restricted to certain types of water, and form most valuable biological indicators of their respective water masses, which are often not easily distinguishable by the usual hydrological features, such as salinity and temperature.

Bottom-living invertebrates form the food of many fish and are specialized for life in different grades of bottom material, from fine mud to coarse gravel, and normal metamorphosis from the larval stage may only occur on the appropriate substratum. Study of the available food in the different deposits reveals considerable variations. The topography of the sea bottom is also important in connexion with water movements. There are indications that the embay. ments resulting from submerged valleys may cause submarine waves, with consequent upwelling of nutrient-laden water into the photic layers.

With the exception of insects, all the major groups of animals are represented, many of them exclusively, in the sea. The problems they present for inquiry to the systematist, morphologist, ecologist, parasitologist, embryologist and geneticist are without limit, and so, from this point of view, are the facilities of the Plymouth Laboratory. From a study of structure there is a natural transition to that of life-histories, food and feeding, breeding and growth, and the general relationships between the animal and the environment. Apart from the bearing of such studies on food fishes and shellfish, they provide essential knowledge for combating the activities of marine boring animals and of fouling organisms. During the War the demand for raw material, such as alginic acid, agar and mannitol, from seaweeds, gave a sudden stimulus to research on the life-history and growth-rate of intertidal weeds, of which very little was known. Extension of work into estuarine waters has provided physiological problems of the first importance and data of value in assessing pollution. Finally, by the working out of new methods of collection and analysis, the Laboratory has played an important part in the success of deep-sea expeditions carried out by vessels of many countries.

While the work of the staff at Plymouth is most varied, as revealed in the foregoing brief survey, it is greatly increased by that of the continuous stream of visiting workers from all countries which has always been encouraged in every way possible. To them in particular has been due the increasing volume of physiological work for which the rich supply of animal life provides material often unobtainable elsewhere, such as the spider crab, Maia, used for nerve physiology and studies on the respiratory pigment, hæmocyanin, the squids and cuttlefish with their giant nerve fibres, sea anemones with their simple nerve net, and the dogfish which has provided material for elucidation of the function of the lateral line and of the labyrinth.

From the simple beginnings of accommodation, staff and programme in 1888, the Plymouth Laboratory has been gradually raised to its present commanding position among research institutions, above all by the careful guidance of Dr. E. J. Allen, its director for forty-two years, and of his successor for an all too brief period, Dr. Stanley Kemp. With their names will always be associated that of Dr. G. P. Bidder, who has given so generously in wisdom and money. The present buildings can accommodate some forty workers, including the present twelve members of the permanent staff. It possesses an admirable library and an aquarium. There are two research vessels, a $25 \mathrm{ft}$. motor boat and a $90 \mathrm{ft}$. motor fishing vessel used for investigations at sea and also for collection of specimens and for stocking the aquarium. During the Easter vacation, they also assist in the courses for students which are so important a feature in the work of the Laboratory, and which have guided many young zoologists into a life-work of fruitful research either in the universities or in marine laboratories.

The Plymouth Laboratory, in the words of its present director, F. S. Russell, "aims to give facilities for any research, not necessarily only biological, on problems for which the sea can provide the materials or the environment required. Its position is unique, lying as it does between the extremes of a fishery research laboratory and of an oceanographical institution, yet serving both, and at the same time offering facilities for visitors like the laboratory at. Naples on whose pattern it was first founded. Let us hope it may continue to hold this focal position and attract all those interested in the science of the sea and indeed of life itself."

\section{THE VIENNA ACADEMY OF SCIENCES (1847-1947)}

$\mathrm{T}$

"HE "Kaiserliche Akademie der Wissenschaften" of Vienna was founded by Kaiser Ferdinand I on May 14, 1847. Although not a State institution, the Academy is conducted under the ægis of, and is endowed by, the State. It consists of two Sections (Klassen), the Mathematical and Natural Science Section for mathematics, natural science, medicine and technical science, and the Philosophical and Historical Section for philosophy, history and archæology, art and music, language and literature, geography and ethnology, law, political science and economics. The Sections meet separately every fortnight for the consideration and discussion of scientific subjects, and they have a joint session once a month.

The work of the Academy is carried out under the continuous supervision of a commission for each scientific subject or for a particular research undertaking, this commission advising on the equipment, methods and problems of the undertaking, and on the choice of suitable personnel. From the scientific point of view, the main work of the Academy is under the care of its members, and it maintains a scientific liaison with various State institutes, in particular with those of the University of Vienna. Moreover, the Academy has several institutes under its direction, especially on the scientific side.

Each Section of the Academy has 33 members and 80 corresponding members, of whom 35 are Austrians and 45 foreign nationals, and there are also 8 honorary members in each Section. Provision is also made for the election of eight honorary members of the whole Academy, and these would be mostly highly placed dignitaries of the State who have rendered service to research or to the advancement of the interests of the Academy, or distinguished men of learning of national or international repute. Corresponding members are entitled to take part in open meetings of the Sections, but they are not automatically promoted to full membership of the Academy. Places rendered vacant by the death of members or corresponding members 